NBER WORKING PAPER SERIES

\title{
LIFE-CYCLE VARIATION IN THE ASSOCIATION BETWEEN CURRENT AND LIFETIME EARNINGS
}

\author{
Steven Haider \\ Gary Solon \\ Working Paper 11943 \\ http://www.nber.org/papers/w11943
NATIONAL BUREAU OF ECONOMIC RESEARCH 1050 Massachusetts Avenue
Cambridge, MA 02138
January 2006

The authors gratefully acknowledge grant support from the National Institute on Aging (2-P01 AG 10179). They also are grateful for advice from the American Economic Review editor and referees, John Bound, Charlie Brown, Art Goldberger, Nathan Grawe, Jacob Klerman, Luigi Pistaferri, Matthew Shapiro, Mel Stephens, Bob Willis, Jeff Wooldridge, and seminar participants at the University of Michigan, American University, the University of California at Berkeley, the University of California at Davis, Harvard's Kennedy School, the National Bureau of Economic Research, Ohio State University, Penn's Wharton School, the Society of Labor Economists, the University of Toronto, and Western Michigan University. The views expressed herein are those of the author(s) and do not necessarily reflect the views of the National Bureau of Economic Research.

(C2006 by Steven Haider and Gary Solon. All rights reserved. Short sections of text, not to exceed two paragraphs, may be quoted without explicit permission provided that full credit, including (C notice, is given to the source. 
Life-Cycle Variation in the Association between Current and Lifetime Earnings

Steven Haider and Gary Solon

NBER Working Paper No. 11943

January 2006

JEL No. D3, J3

\begin{abstract}
Researchers in a variety of important economic literatures have assumed that current income variables as proxies for lifetime income variables follow the textbook errors-in-variables model. In an analysis of Social Security records containing nearly career-long earnings histories for the Health and Retirement Study sample, we find that the relationship between current and lifetime earnings departs substantially from the textbook model in ways that vary systematically over the life cycle. Our results can enable more appropriate analysis of and correction for errors-in-variables bias in a wide range of research that uses current earnings to proxy for lifetime earnings.

Steven Haider

Department of Economics

Michigan State University

East Lansing, MI 48824

haider@msu.edu

Gary Solon

Department of Economics

University of Michigan

Ann Arbor, MI 48109

and NBER

gsolon@umich.edu
\end{abstract}




\section{Life-Cycle Variation in the Association between Current and Lifetime Earnings}

\section{Introduction}

In the year 2003 alone, the American Economic Review's refereed issues contained 14 articles reporting regression analyses involving individual or family income variables, and the May Proceedings issue contained almost that many again. In some cases, the income variables were dependent variables; in others, they were regressors used to explain dependent variables ranging from child health in the United States to borrowing and lending behavior in Ghana. Without exception, the measured income variables were short-term values even though, in most cases, it appeared that the relevant economic construct was a longer-term value.

Many influential economic studies have recognized that the use of current income as a proxy for long-run income can generate important errors-in-variables biases.

Perhaps the most famous examples are the seminal studies by Modigliani and Brumberg (1954) and Friedman (1957), which analyzed the properties of consumption functions estimated with current rather than permanent income variables as the regressors. Another instance is the literature (e.g., Lillard, 1977) suggesting that inequality as measured in cross-sections of annual earnings overstates the inequality in lifetime earnings. A recent offshoot of that literature - exemplified by Gottschalk and Moffitt (1994), Haider (2001), and Baker and Solon (2003) - has attempted to partition the upward trend in earnings inequality into persistent and transitory components. Still another recent example is the burgeoning literature on intergenerational income mobility (surveyed in Solon, 1999), which has found that the association between parents' and children's long-run income is 
susceptible to dramatic underestimation when current income variables are used as proxies for long-run income.

Nevertheless, applied researchers often ignore the distinction between current and long-run income. Most researchers who do attend to the issue assume the textbook errors-in-variables model and impute the noise-to-signal ratio by estimating restrictive models of income dynamics on the basis of short panels of income data spanning only a segment of the life cycle. ${ }^{1}$ In this paper, we reconsider the appropriateness of the textbook errors-in-variables model, and we find that it does not accurately characterize current earnings as a proxy for lifetime earnings. Thanks to a remarkable new data set, we are able to generate detailed evidence on the association between current and lifetime earnings, including its evolution over the life cycle, without having to resort to an arbitrary specification of the earnings dynamics process.

Our empirical analysis uses the 1951-1991 Social Security earnings histories of the members of the Health and Retirement Study sample. Despite some limitations discussed in section III, these data provide nearly career-long earnings histories, which are based on relatively accurate administrative data and pertain to a broadly representative national sample. In section II, we develop simple models to illustrate some important aspects of the association between current and lifetime earnings and to demonstrate the implications for errors-in-variables biases in applied econometric research. In section III, we describe the data set and our econometric methods. In section IV, we present our evidence on the connections between annual and lifetime earnings. Section V summarizes our findings and illustrates their usefulness with a brief application to intergenerational earnings mobility.

\footnotetext{
${ }^{1}$ See Mazumder (2001) for a relatively sophisticated recent example.
} 


\section{Models}

Following Friedman (1957), most analyses of current income variables as proxies for unobserved lifetime income variables have adopted the textbook errors-in-variables model

$$
y_{i t}=y_{i}+v_{i t}
$$

where $y_{i t}$ is a current income variable, such as log annual earnings, observed for individual $i$ in period $t ; y_{i}$ is a long-run income variable, such as the log of the present discounted value of lifetime earnings; and $v_{i t}$, the measurement error in $y_{i t}$ as a proxy for $y_{i}$, is assumed to be uncorrelated with $y_{i}$ (and each of its determinants). Often, the current income variable $y_{i t}$ has been adjusted for stage of life cycle with a regression on a polynomial in age or experience or by subtracting out the cohort mean. Throughout this section, we will suppress intercepts by expressing all variables as deviations from their population means.

The textbook errors-in-variables model in equation (1) is effectively a regression model that assumes the slope coefficient in the regression of $y_{i t}$ on $y_{i}$ equals 1 . One familiar implication of that restriction is that, if $y_{i t}$ proxies for $y_{i}$ as the dependent variable in a linear regression equation, ordinary least squares (OLS) estimation of that regression equation consistently estimates the equation's slope coefficients. Another well-known implication is that, if $y_{i t}$ proxies for $y_{i}$ as the sole explanatory variable in a simple regression equation, the probability limit of the OLS estimator of the equation's slope coefficient equals the true coefficient times an attenuation factor equal to $\operatorname{Var}\left(y_{i}\right) /\left[\operatorname{Var}\left(y_{i}\right)+\operatorname{Var}\left(v_{i t}\right)\right]$. 
These oft-used results no longer apply if the textbook errors-in-variables model incorrectly characterizes the relationship between current and lifetime income. In part A of this section, we explain our reasons for suspecting that the slope coefficients in regressions of current income variables on lifetime variables vary systematically over the life cycle and do not generally equal 1 . In part B, we show how such departures from the textbook model alter the standard results on errors-in-variables bias.

\section{A. Life-cycle variation}

Several fragments of evidence suggest that the association between current and lifetime income variables varies over the life cycle. Bjorklund (1993), the closest predecessor to our study, uses Swedish income tax data from 1951-1989 to conduct a direct comparison of current and lifetime income. He finds a strong life-cycle pattern in the correlation between current and lifetime income. In his words, "the correlations are quite low - and in some cases even negative - up to around 25 years of age and are rather high after 35 years of age. In general the correlations are around 0.8 after the age of $35 . "$ Unfortunately, the correlations in income levels reported by Bjorklund do not map directly into magnitudes of errors-in-variables biases in the sorts of regression estimation that economists commonly do. In the next subsection, we develop measures of association between current and lifetime earnings that do have direct implications for errors-in-variables biases.

Another indication of life-cycled-related departures from the textbook errors-invariables model, noted by Jenkins (1987) and Grawe (forthcoming), involves the estimation of intergenerational mobility models such as the regression of son's log 
lifetime earnings on father's log lifetime earnings. If son's log annual earnings as a proxy for the dependent variable obeyed the textbook errors-in-variables model, the estimated intergenerational elasticity would have the same probability limit regardless of the age at which the son's earnings were observed. On the other hand, if the slope coefficient in the regression of son's log annual earnings on son's log lifetime earnings deviates from 1 in a way that evolves over the life cycle, then analyses observing sons' earnings at different ages will yield systematically different elasticity estimates. Solon's (1999) survey of the intergenerational mobility literature reveals precisely such a pattern - the studies that estimate the smallest elasticities tend to be those that observe sons' earnings early in their careers. Correspondingly, several studies (e.g., Reville, 1995) that have explicitly investigated the effects of varying the ages at which sons' earnings are observed have found that the estimated intergenerational elasticities increase substantially as the sons' earnings are observed further into their careers.

Notwithstanding the strong tradition of assuming that current income variables as proxies for lifetime income variables follow the textbook errors-in-variables model, indications that this assumption is false should not be surprising. Any realistic model of income evolution over the life cycle would contradict the traditional assumption. As an extremely simple example, suppose that $y_{i t}$, the log real earnings of worker $i$ in year $t$ of his career, follows

$$
y_{i t}=\alpha_{i}+\gamma_{i} t
$$

where initial log earnings $\alpha_{i}$ varies across the population with variance $\sigma_{\alpha}^{2}$ and the earnings growth rate $\gamma_{i}$ varies across the population with variance $\sigma_{\gamma}^{2}$. Heterogeneity in earnings growth is a natural consequence of heterogeneity in human capital investment, 
and its empirical importance has been documented by Mincer (1974), Baker (1997), Haider (2001), and Baker and Solon (2003) among others. For simplicity, assume zero covariance between $\alpha_{i}$ and $\gamma_{i}$, infinite lifetimes, and a constant real interest rate $r>\gamma_{i}$. Then the present discounted value of lifetime earnings is

$$
V_{i}=\sum_{s=0}^{\infty} \exp \left(\alpha_{i}+\gamma_{i} s\right)(1+r)^{-s} \cong \exp \left(\alpha_{i}\right)\left[(1+r) /\left(r-\gamma_{i}\right)\right]
$$

and the log of the present value of lifetime earnings is thus

(4) $\log V_{i} \cong \alpha_{i}+r-\log r+\frac{\gamma_{i}}{r}$.

It follows that the slope coefficient in the regression of current log earnings on the log of the present value of lifetime earnings is

$$
\lambda_{t} \equiv \frac{\operatorname{Cov}\left(\log V_{i}, y_{i t}\right)}{\operatorname{Var}\left(\log V_{i}\right)} \cong \frac{\sigma_{\alpha}^{2}+\left(t \sigma_{\gamma}^{2} / r\right)}{\sigma_{\alpha}^{2}+\left(\sigma_{\gamma}^{2} / r^{2}\right)}
$$

The main thing to note about this result is that, contrary to the textbook errors-invariables model, $\lambda_{t}$ generally does not equal 1 . Instead, it starts at a value less than 1 at the outset of the career and then increases monotonically over the life cycle. It reaches 1 when $t=1 / r$ and then exceeds 1 afterwards. The intuition is that the workers with high lifetime earnings tend to be those with high earnings growth rates. Consequently, when comparing the current earnings of those with high and low lifetime earnings, an earlycareer comparison tends to understate their gap in lifetime earnings, and a late-career comparison may overstate it. Note that the common practice of adjusting current earnings for the central tendency of earnings growth over the life cycle does not undo this result. The result is due to heterogeneous variation around the central tendency. 
Of course, the exact result in equation (5) is particular to the very simple assumptions of the model. A more realistic model would incorporate many additional features including transitory earnings fluctuations, nonzero covariance between initial earnings and earnings growth, nonlinear growth, and shocks with permanent effects. While these features would lead to a more complex relationship between $\lambda_{t}$ and $t$, they clearly would not overturn the main qualitative results - that $\lambda_{t}$ does not generally equal 1 and should be expected to vary over the life cycle.

Figure 1 provides a pictorial version of the argument. The figure contains the life-cycle log earnings trajectories of workers 1 and 2, with worker 2 attaining higher lifetime earnings. Both trajectories display the familiar concave shape documented and analyzed by Mincer (1974), and worker 2 experiences more rapid earnings growth through most of the life cycle. The horizontal lines depict the log of the annuitized value of each worker's present discounted value of lifetime earnings. The difference between the two workers' log lifetime earnings therefore is simply the vertical distance between the two horizontal lines. But how well is that difference estimated if it is proxied by the difference in log earnings at a particular age? If the worker with higher lifetime earnings has a steeper earnings trajectory, then the current earnings gap between the two workers early in their careers tends to understate their gap in lifetime earnings (and could even have the opposite sign). As the workers mature, this downward bias becomes less severe until age $t^{*}$, when the vertical distance between the current earnings trajectories equals the distance between the horizontal lines. That is the age at which the textbook errors-invariables model is correct. For at least some of the life cycle beyond that age, the gap in current earnings tends to overstate the gap in lifetime earnings. 
B. Implications for errors-in-variables biases

Suppose we wish to estimate the regression model

$$
y_{i}=\beta^{\prime} X_{i}+\varepsilon_{i}
$$

where the error term $\varepsilon_{i}$ is uncorrelated with the regressor vector $X_{i}$. Starting with the case of left-side measurement error, suppose that $y_{i}$ is the log of lifetime earnings, which is not observed and hence is proxied by $y_{i t}, \log$ annual earnings at age $t$. In accordance with the discussion in the preceding subsection, we do not assume the textbook errors-invariables model in equation (1). Instead, we generalize that model to

$$
y_{i t}=\lambda_{t} y_{i}+v_{i t}
$$

where $\lambda_{t}$, the slope coefficient in the linear projection of $y_{i t}$ on $y_{i}$, need not equal 1 and may vary over the life cycle. By construction, $v_{i t}$ is uncorrelated with $y_{i}$, and we will continue to maintain the textbook model's assumption that it also is uncorrelated with each separate determinant of $y_{i}\left(X_{i}\right.$ and $\left.\varepsilon_{i}\right) .^{2}$ Then, if OLS is applied to the regression of $y_{i t}$ on $X_{i}$,

$$
y_{i t}=\lambda_{t} \beta^{\prime} X_{i}+\left(\lambda_{t} \varepsilon_{i}+v_{i t}\right)
$$

the probability limit of the estimated coefficient vector for $X_{i}$ is $\lambda_{t} \beta$ instead of $\beta$. In the textbook case where $\lambda_{t}=1$, measurement error in the dependent variable does not result in inconsistent estimation of $\beta$. More generally, however, the OLS estimator is

\footnotetext{
${ }^{2}$ When this assumption fails, as it sometimes does, neither the textbook analysis nor our extension is applicable. When $\operatorname{Var}\left(v_{i t}\right)=0$, equation (7) specializes to the rescaling of variables often discussed in introductory econometrics textbooks (e.g., section 2.4 of Wooldridge, 2006). See section 4 of Angrist and Krueger (1999) for an excellent overview of errors in variables, including non-classical measurement error.
} 
inconsistent, and the inconsistency varies as a function of the age at which annual earnings are observed.

Moving on to the case of right-side measurement error, suppose that the log of lifetime earnings is one element $x_{i}$ in the regressor vector $X_{i}$. Because $x_{i}$ is not observed, it is proxied by $x_{i t}, \log$ annual earnings at age $t$. Analogously to equation (7) for $y_{i t}$, we express the linear projection of $x_{i t}$ on $x_{i}$ as

$$
x_{i t}=\lambda_{t} x_{i}+v_{i t}
$$

where $v_{i t}$ again is assumed to be uncorrelated with $X_{i}$ and $\varepsilon_{i}$. If $x_{i}$ is the only element in $X_{i}$ and OLS is applied to the linear regression of $y_{i}$ on $x_{i t}$, the probability limit of the estimated slope coefficient is

(10) $\operatorname{plim} \hat{\beta}=\frac{\operatorname{Cov}\left(x_{i t}, y_{i}\right)}{\operatorname{Var}\left(x_{i t}\right)}=\theta_{t} \beta$

where

(11) $\theta_{t} \equiv \frac{\operatorname{Cov}\left(x_{i t}, x_{i}\right)}{\operatorname{Var}\left(x_{i t}\right)}=\frac{\lambda_{t} \operatorname{Var}\left(x_{i}\right)}{\lambda_{t}^{2} \operatorname{Var}\left(x_{i}\right)+\operatorname{Var}\left(v_{i t}\right)}$

The inconsistency factor $\theta_{t}$, sometimes referred to as the "reliability ratio," is most simply interpreted as the slope coefficient in the "reverse regression" of $x_{i}$ on $x_{i t}$. In the textbook case where $\lambda_{t}=1$, this factor simplifies to the familiar attenuation factor $\operatorname{Var}\left(x_{i}\right) /\left[\operatorname{Var}\left(x_{i}\right)+\operatorname{Var}\left(v_{i t}\right)\right]$. More generally, the factor $\theta_{t}$ also depends on the value of $\lambda_{t}$. Indeed, with $\lambda_{t}<1$ and sufficiently small $\operatorname{Var}\left(v_{i t}\right) / \operatorname{Var}\left(x_{i}\right), \theta_{t}$ can exceed 1 so that the errors-in-variables bias is an amplification bias rather than an attenuation bias. 
Two further results about right-side measurement error are worth noting. First, if $x_{i}$ is just one element in the regressor vector $X_{i}$, the attenuation factor for its estimated coefficient is the same as the last expression in equation (11) except with $\operatorname{Var}\left(x_{i}\right)$ replaced by the residual variance from the auxiliary regression of $x_{i}$ on the other regressors in $X_{i}$. Second, if the measurement error in $x_{i t}$ as a proxy for $x_{i}$ is treated with an instrumental variable (IV) correlated with $x_{i}$ but uncorrelated with $\varepsilon_{i}$ or $v_{i t}$, the probability limit of the conventional IV estimator of the coefficient of $x_{i}$ is the coefficient divided by $\lambda_{t}{ }^{3}$

The results presented in this subsection deliver two key messages. First, with plausible departures from the textbook errors-in-variables assumptions, the familiar textbook results about OLS and IV estimation are overturned. Measurement error in the dependent variable is not innocuous for consistency, and measurement error in the explanatory variable can induce either amplification or attenuation inconsistency in OLS estimation as well as in IV estimation. Second, some of the estimation inconsistencies from using log annual earnings as a proxy for log lifetime earnings can be summarized with just two simple parameters: the slope coefficient in the "forward regression" of log annual earnings on log lifetime earnings and the slope coefficient in the "reverse regression" of log lifetime earnings on log annual earnings. In section IV, we will estimate those two parameters and examine how they vary over the life cycle.

\footnotetext{
${ }^{3}$ The inconsistency of conventional IV estimation in the presence of non-classical measurement error has been discussed previously by Kane, Rouse, and Staiger (1999), Bound and Solon (1999), and Kim and Solon (2005).
} 


\section{Data and Methods}

A. Data

Most U.S. studies of the relationship between current and lifetime income variables have been based on longitudinal survey data from only a limited portion of the respondents' careers. In contrast, like Bjorklund's (1993) study of Swedish income tax data, our study is based on nearly career-long earnings histories. This information is now available for a U.S. sample because, in accordance with an agreement with the Social Security Administration, the University of Michigan's Survey Research Center asked the participants in its Health and Retirement Study (HRS) to permit access to their Social Security earnings histories for 1951-1991. ${ }^{4}$ The HRS sample is a national probability sample of Americans born between 1931 and 1941, and about 3/4 of the respondents agreed to permit access to their Social Security earnings histories. As shown in Haider and Solon (2000), in terms of observable characteristics, the respondents that granted access appear to be surprisingly representative of the complete sample. The earnings data supplied by the Social Security Administration round the earnings observations to the nearest hundred dollars, with a distinction made between zero and positive amounts less than $\$ 50$.

Our analysis is for male HRS respondents born between 1931 and 1933, who were about 19 years old at the beginning of the 1951-1991 earnings period and about 59 at the end. Thus, for the 821 men in our analysis, we have annual earnings information

\footnotetext{
${ }^{4}$ Because of the highly confidential nature of the data, the earnings histories are not part of the HRS public release data sets, but are provided only through special permission from the Survey Research Center. For information on accessing "HRS restricted data," see the HRS website http://hrsonline.isr.umich.edu. For more general information on the HRS, see the website or Juster and Suzman (1995).
} 
for every year over the major portion of their careers. ${ }^{5}$ The other main strength of our data set is that the Social Security earnings histories tend to be more accurate than the survey reports of earnings used in most previous research. Indeed, Bound and Krueger's (1991) influential study of errors in earnings reports in the Current Population Survey used Social Security earnings data as the "true" values against which the Current Population Survey measures were compared.

The strengths of the Social Security earnings data are accompanied by two serious limitations. First, the earnings data pertain only to jobs covered by Social Security. According to Social Security Administration (1999, table 3.B2), the percentage of earnings covered by Social Security has exceeded $80 \%$ ever since the coverage extensions effected by 1957 and exceeded 85\% over most of our sample period. Between 1951 and 1956, however, this percentage ranged between 66 and 79\%. Accordingly, in addition to our analyses for 1951-1991, we also will report results for 1957-1991.

Second, the Social Security earnings in our data are measured only up to the maximum amount subject to Social Security tax. In some years, the proportion of observations that are "right-censored" is quite large. For the 821 men in our sample, table 1 displays the median observed earnings, the percentage in the sample with zero earnings, the taxable limit, and the percentage with earnings at the taxable limit for each year from 1951 to 1991 . The table shows that, in the early years, very few sample members are earning enough to approach the taxable limit. As their earnings grow over their careers, however, the taxable limit becomes more constraining, especially in the

\footnotetext{
${ }^{5}$ This sample is restricted to workers with positive earnings in at least 10 years during 1951-1991. This criterion, which excludes only 33 individuals, is less restrictive than the usual practice in survey-based earnings dynamics studies of requiring positive earnings in every year (e.g., Abowd and Card, 1989; Baker, 1997). Within this sample, our main analysis includes years of zero earnings, but we also will report results from an analysis based only on the positive earnings observations.
} 
years when the taxable limit is low relative to the general earnings distribution. The worst year is 1965 , when $62 \%$ of the sample is right-censored. Afterwards, the degree of censorship lessens as the taxable limit is progressively increased. By 1991, only $9 \%$ of the sample is right-censored. Although some previous studies of current and lifetime earnings have used annual earnings data with less severe right-censorship, their observation of earnings usually has been limited to relatively short segments of the life cycle. In effect, they have used restrictive models of earnings dynamics to impute missing earnings data over most years of their sample members' careers.

If not for the right-censorship, we would follow Bjorklund's (1993) approach of directly summarizing the observed joint distribution of annual and lifetime earnings. Because of the right-censorship, however, we are forced instead to estimate the joint distribution in a way that imputes the censored right tails of the annual earnings distributions. We describe our methods in the next subsection.

\section{B. Econometric methods}

As explained above in section II.B, our ultimate goal is to summarize the association between annual and lifetime earnings in terms of two types of parameters. One is $\lambda_{t}$, the slope coefficient in the regression of log earnings in year $t$ on the log of the present value of lifetime earnings. The other is $\theta_{t}$, the slope coefficient in the reverse regression of log lifetime earnings on log earnings in year $t$. If we had complete data, we would estimate these parameters simply by applying least squares to the forward and reverse regressions of the relevant variables. 
Because of the censorship of the Social Security earnings data at the taxable limit, however, we cannot observe the exact value of annual earnings in the cases where earnings are right-censored and furthermore, in those cases, we also cannot compute the present value of lifetime earnings. We therefore apply a three-step procedure for estimating the $\lambda$ and $\theta$ coefficients. First, we use a limited-dependent-variable model to estimate the joint distribution of uncensored annual earnings in the 41 years from 1951 through 1991. Second, drawing from that estimated joint distribution, we generate a simulated sample of uncensored earnings histories, for which we can calculate the present discounted value of lifetime earnings. Third, using the uncensored earnings data for that sample, we apply least squares to the forward and reverse regressions to obtain our estimates of the $\lambda$ and $\theta$ parameters.

The key assumption in our first step is that the uncensored values of log annual earnings over the 41 years from 1951 to 1991 follow a multivariate normal distribution. Given this variant of the traditional Tobit assumption for limited dependent variables, the joint distribution of the 41 annual earnings variables can be fully characterized by the mean and variance of log earnings for each year and the cross-year autocorrelations of $\log$ earnings for every pair of years.

To estimate the year-specific means and variances for our sample cohort born in 1931-1933, we simply apply the conventional cross-sectional Tobit maximum likelihood estimator separately for each year from 1951 to 1991 . The only regressor in each year's equation is 1 , the coefficient of which is the intercept. The estimated intercept is our estimate of the cohort's mean log earnings in that year. In our main analysis, we use a two-limit Tobit model. The right-censorship threshold is the Social Security taxable limit 
for that year. The left-censorship threshold is $\$ 50$. Observations of zero earnings and of positive earnings less than $\$ 50$ are both included as observations left-censored at $\$ 50{ }^{6}$

Having estimated each year's mean and variance in the cross-sectional Tobits, we still need to estimate the autocorrelations between years. To obtain those estimates, we apply the conventional bivariate Tobit maximum likelihood estimator separately for each of the $41 \times 40 / 2=820$ distinct pairs of years in our 1951-1991 period. With those autocorrelations estimated along with the mean and variance for every year, we have an estimated version of the entire joint distribution of uncensored annual earnings over all 41 years.

In the second step of our procedure, we use our estimated joint distribution of uncensored earnings for 1951-1991 to perform the following simulation. First, we take 4,000 random draws from the estimated joint distribution of the 41 years of annual earnings. ${ }^{7}$ Then, for each of the 4,000 simulated earnings histories, we calculate the present discounted value of lifetime earnings. In the main version of the simulation, we perform the discounting by (1) using the personal consumption expenditures deflator to convert each year's nominal earnings to a real value and (2) assuming a constant real interest rate of 0.02 . In the end, we have a simulated sample of 4,000 observations for which we observe the present discounted value of lifetime earnings as well as each year's earnings.

\footnotetext{
${ }^{6}$ In the simulation described below, our treatment of zero-earnings observations as left-censored observations from a lognormal distribution causes our simulated observations to include no zeros, but instead small annual earnings values less than $\$ 50$. The purpose of the simulation is to generate observations for the present discounted value of lifetime earnings. For that purpose, the difference between annual earnings of zero or a few dollars is of practically no consequence.

${ }^{7}$ To implement the simulation, we need the estimated autocovariance matrix to be positive semi-definite (as the true one must be). Our procedure for imposing the restriction of positive semi-definiteness is described in the appendix to this paper.
} 
Finally, for this sample of 4,000 individuals, we apply OLS to the regression of each year's log annual earnings on the log of the present value of lifetime earnings, and

thereby produce a $\hat{\lambda}_{t}$ for each year from 1951 to 1991 . Similarly, we obtain a $\hat{\theta}_{t}$ for each year by applying OLS to the reverse regression of the log of the present value of lifetime earnings on each year's log annual earnings. Plotting each of these coefficient estimates over time depicts the life-cycle trajectory of the association between current and lifetime earnings in a way that translates directly into implications for errors-invariables biases.

\section{Empirical Results}

In the first step of our estimation procedure, the Tobit analysis described above results in a $41 \times 41$ estimated autocovariance matrix for log annual earnings from 1951 to 1991. The full matrix is provided in matrix.xls in a zip file available at http://www.msu.edu/ haider. Table 2 shows the estimated autocorrelations for 19751984, a period when our cohort born in 1931-1933 is between the ages of about 43 and 52. As shown in the second column of table 3 , the first-order autocorrelations over this period average to 0.89 , the second-order autocorrelations average to 0.82 , the third-order autocorrelations average to 0.78 , and so forth. Table 3 also displays estimated autocorrelations from two other studies of administrative data. The most comparable results reported in Baker and Solon's (2003) study of Canadian income tax data are the autocorrelations over the 1985-1992 period for the cohort born in 1942-1943. Their average autocorrelations, shown in the third column, are fairly similar to ours, but somewhat lower. As shown in the fourth column, the estimates from Bohlmark and 
Lindquist (2005), a replication of our study based on Swedish income tax data, are closer to ours than to Baker and Solon's. Note that this resemblance between other studies' estimates and ours occurs even though the other studies use uncensored data and therefore can estimate the autocorrelations directly without imposing distributional assumptions. ${ }^{8}$ We find it reassuring that, despite the omission of earnings not covered by Social Security and the imputation of right-censored values, our autocorrelation estimates are similar to those from other data sets. Most of these estimated autocorrelations are somewhat higher than those reported by Baker (1997) and Haider (2001) in their analyses of the Panel Study of Income Dynamics, but the survey-based estimates may be biased downward by reporting error.

Another relevant comparison is to an alternative earnings variable available for our sample for 1980-1991. For those years, in addition to the Social Security earnings data, the Survey Research Center also has obtained earnings data from employers' W-2 reports to the Internal Revenue Service. Unlike the Social Security data, the W-2 variable includes earnings not covered by Social Security, and it is right-censored (for confidentiality reasons) at $\$ 125,000$, which is far less constraining than the Social Security taxable limits listed in table 1 . On the other hand, the W-2 variable leaves out self-employment earnings and earnings allocated to 401(k) pensions. As shown in the fifth column of table 3, when we use the W-2 data to reestimate our Tobits for 19801991, the first-order autocorrelations average to 0.89 , the second-order autocorrelations average to 0.83 , and the third-order autocorrelations average to 0.79 . As shown in the last column, the corresponding average autocorrelations for the Social Security earnings

\footnotetext{
${ }^{8}$ Also like these other studies, we find that earnings autocorrelations are somewhat smaller early in the life cycle.
} 
variable over the same period are $0.91,0.85$, and 0.81 . The idiosyncrasies of the alternative earnings measures do not appear to generate major discrepancies in the estimated persistence of earnings. ${ }^{9}$

In the second step of our estimation procedure, we perform the simulation in which we take 4,000 draws from the estimated joint distribution of the 41 years of annual earnings. Then, using the resulting sample of 4,000 uncensored earnings histories, our third step summarizes the connection between annual and lifetime earnings by estimating the forward and reverse regressions between the logs of annual and lifetime earnings.

The top portion of figure 2 plots our estimates of $\lambda_{t}$, the slope coefficient in the regression of $\log$ annual earnings at time $t$ on the log of the present value of lifetime earnings. To focus on the life-cycle variation in $\lambda_{t}$, we express $t$ on the horizontal axis as year minus 1932, which gives the approximate age of our 1931-1933 cohort in each year. ${ }^{10}$ In contrast to the textbook assumption that $\lambda_{t}$ equals 1 throughout the life cycle, $\hat{\lambda}_{t}$ begins at 0.24 at age 19 , increases steadily until it rises to about 1 at age 32 , and then declines some in the late forties. The main implication is that, contrary to the textbook errors-in-variables model, using log current earnings to proxy for log lifetime earnings as the dependent variable can induce an errors-in-variables bias. Most importantly, using current earnings in the twenties causes a large attenuation bias. A constructive

\footnotetext{
${ }^{9}$ Perhaps the similarity of the autocorrelation estimates should not be a surprise. If one thinks of the log of covered earnings as the sum of log total earnings and the log of the proportion covered, one would expect the autocorrelation of log covered earnings to be approximately a weighted average of the autocorrelations for log total earnings and log coverage. Presumably, both of these autocorrelations are highly positive. If they are not very different from each other, then "averaging in" the coverage autocorrelation will not produce a large bias in estimating the earnings autocorrelation.

${ }^{10}$ The point estimates plotted in figure 2 and the associated standard error estimates are tabulated in our appendix, which also describes our bootstrap procedure for estimating the standard errors.
} 
implication is that the bias is small if one uses current earnings between the early thirties and the mid forties, when the textbook assumption that $\lambda_{t}=1$ is reasonably accurate.

The lower portion of figure 2 shows the estimated life-cycle trajectory of the reliability ratio $\theta_{t}$, the relevant parameter for assessing errors-in-variables bias from using log annual earnings to proxy for log lifetime earnings as the explanatory variable in a simple regression. $\hat{\theta}_{t}$ begins at only about 0.2 , increases to a fairly flat peak averaging about 0.65 between the late twenties and mid forties, and then decreases. Our discussion in section II.B showed that theoretically the errors-in-variables bias could be either an attenuation bias or an amplification bias. Our empirical results, however, confirm the conventional presumption that using current earnings to proxy for lifetime earnings as a regressor induces an attenuation bias. The bias is especially large if current earnings are measured early in the life cycle. There is a wide age range in mid-career when the errorsin-variables bias stays about the same, but it remains quite substantial even in that range.

To check the robustness of our main results, we have carried out a series of sensitivity analyses, the results of which are displayed in figure 3 . The first is motivated by the question of how to treat years of zero earnings. Our main results are based on two-limit Tobit estimates that retain observations of zero earnings in the analysis. Because most previous analyses of earnings dynamics, however, have excluded observations of zero earnings, we supplement our main analysis with another that excludes the zeros, codes positive earnings less than $\$ 50$ as $\$ 25$, and estimates one-limit Tobits with only right-censorship. As shown in table 1, zero earnings are especially prevalent in the early years of our sample, both because many of our sample members are not yet working for pay and because the Social Security system's coverage is less 
extensive before 1957. We therefore conduct this analysis only for 1957-1991.

Excluding the zeros changes the estimates of the variances and autocovariances in log annual earnings, but because those changes are roughly proportional, the estimated autocorrelations are similar to those in the main analysis. Accordingly, the new estimates of $\lambda_{t}$ and $\theta_{t}$ shown in figure 3 are similar to the estimates from our main analysis repeated from figure 2 .

Our second and third robustness checks explore the sensitivity of our results to our choice of interest rate series. In our main simulation, we calculated the present discounted value of lifetime earnings by (1) using the personal consumption expenditures deflator to convert each year's nominal earnings to a real value and (2) assuming a constant real interest rate of 0.02 . Our third supplementary analysis uses a real interest rate of 0.04 , and our fourth discounts nominal earnings by a nominal interest rate series, the annual one-year T-note interest rates. ${ }^{11}$ The results shown in figure 3 are quite similar to those based on our original interest rate series.

Fourth, we have checked whether our results are affected by the Health and Retirement Study's oversampling of blacks, Hispanics, and residents of Florida. To do so, we have reestimated the joint distribution of earnings with a Tobit quasi-maximum likelihood procedure that weights each observation's contribution to the likelihood function by its inverse probability of selection into the sample. The resulting Tobit estimates are very similar to those from our original unweighted analysis, and consequently the new estimates of $\lambda_{t}$ and $\theta_{t}$ are again very similar to the main estimates.

\footnotetext{
11 This series is available only back to 1954 . For 1951-1953, we added 0.003 to the interest rates for threemonth T-bills. This adjustment was based on the relationship between the one-year and three-month rates observed for 1954-1959.
} 
Finally, figure 3 includes the results of Bohlmark and Lindquist's (2005) replication of our main analysis based on Swedish income tax data. This comparison is particularly interesting because Bohlmark and Lindquist's data are largely free of the censorship and coverage issues that afflict our U.S. Social Security earnings data. As a result, Bohlmark and Lindquist estimate $\lambda_{t}$ and $\theta_{t}$ directly with the forward and reverse regressions involving log current and lifetime earnings without having to resort to our more complex estimation procedure based on the multivariate normality assumption. Their estimates of $\lambda_{t}$ in the twenties are somewhat higher than ours, but still much less than 1. In general, the patterns of the Swedish and U.S. results are strikingly similar.

\section{$\underline{\text { V. Summary and Discussion }}$}

All of our analyses tell the same story: contrary to the textbook errors-in-variables model usually assumed in applied research, the slope coefficient in the regression of log current earnings on log annual earnings varies systematically over the life cycle and is not generally equal to 1 . We can illustrate the usefulness of our results by applying them to the intergenerational mobility regression in which son's log of lifetime earnings is the dependent variable and father's log of lifetime earnings is the explanatory variable. As summarized in Solon (1999), most recent research in that literature has devoted considerable attention to the right-side measurement error from using short-run proxies for father's lifetime earnings. Our estimates of $\theta_{t}$ shown in figures 2 and 3 confirm the 
literature's presumption that right-side measurement error causes an attenuation inconsistency in OLS estimation of the intergenerational elasticity. ${ }^{12}$

The literature, however, has given much less attention to the left-side measurement error from using short-run proxies for son's lifetime earnings. Presumably, this neglect reflects an assumption by researchers that, in accordance with the textbook errors-in-variables model, left-side measurement error is innocuous for consistency. All our estimates of $\lambda_{t}$ suggest that assumption would be fairly well founded if sons' earnings were measured between the early thirties and mid forties. Many intergenerational mobility studies, however, have measured sons' earnings at earlier ages, and this has substantially affected the findings. Reville (1995), for example, estimates intergenerational elasticities of about 0.25 when he measures the sons' earnings in their twenties, but his estimates start approaching 0.5 when he observes the sons well into their thirties. This is just the pattern one should expect from the trajectories of $\hat{\lambda}_{t}$ in figures 2 and 3. An important implication is that many estimates of the intergenerational earnings elasticity have been subject to substantial attenuation inconsistency from left-side measurement error in addition to the well-known inconsistency from right-side measurement error.

Of course, interpreting evidence on intergenerational earnings mobility is just one example of how our results might be applied. We advise readers, however, to exercise due caution in importing our estimates of $\lambda_{t}$ and $\theta_{t}$ to other earnings data. We already

\footnotetext{
${ }^{12}$ Many researchers have attempted to reduce the attenuation inconsistency by averaging father's log earnings over multiple years. In an analysis summarized in our appendix, we repeat our estimation of $\theta_{t}$ except that the new estimates are for five-year averages of log annual earnings, rather than for single years. Our results strongly support the conclusion of Mazumder $(2001,2005)$ that even estimates based on fiveyear averages of the earnings variable for fathers are subject to a substantial errors-in-variables bias.
} 
have mentioned issues of comparability between administrative and survey data.

Furthermore, the life-cycle trajectories for our U.S. cohort born in 1931-1933 may differ from those for other cohorts and other countries. In addition, as emphasized in Solon (1992), sample selection criteria that affect the sample's dispersion in earnings also affect the measurement error properties of current earnings as proxies for lifetime earnings. Nevertheless, taking account of our evidence on departures from the textbook errors-invariables model should enable better-informed analyses of estimation biases in a wide variety of research that uses current earnings variables as proxies for long-run earnings. 
Table 1. Descriptive Statistics for Nominal Annual Earnings Covered by Social Security

\begin{tabular}{|c|c|c|c|c|}
\hline Year & Median & $\begin{array}{l}\text { Percent with } \\
\text { Zero Earnings }\end{array}$ & Taxable Limit & $\begin{array}{c}\text { Percent at } \\
\text { Taxable Limit }\end{array}$ \\
\hline 1951 & 200 & 37.1 & 3,600 & 1.1 \\
\hline 1952 & 200 & 41.0 & 3,600 & 2.9 \\
\hline 1953 & 100 & 46.0 & 3,600 & 6.5 \\
\hline 1954 & 200 & 43.5 & 3,600 & 10.1 \\
\hline 1955 & 1,300 & 29.1 & 4,200 & 12.1 \\
\hline 1956 & 2,200 & 21.8 & 4,200 & 20.0 \\
\hline 1957 & 3,000 & 10.6 & 4,200 & 29.6 \\
\hline 1958 & 3,100 & 11.9 & 4,200 & 35.1 \\
\hline 1959 & 3,800 & 10.1 & 4,800 & 32.6 \\
\hline 1960 & 4,100 & 11.2 & 4,800 & 39.6 \\
\hline 1961 & 4,200 & 11.9 & 4,800 & 44.2 \\
\hline 1962 & 4,700 & 11.0 & 4,800 & 49.5 \\
\hline 1963 & 4,800 & 10.5 & 4,800 & 53.8 \\
\hline 1964 & 4,800 & 9.7 & 4,800 & 56.4 \\
\hline 1965 & 4,800 & 10.4 & 4,800 & 62.2 \\
\hline 1966 & 6,600 & 8.5 & 6,600 & 50.3 \\
\hline 1967 & 6,600 & 9.0 & 6,600 & 53.5 \\
\hline 1968 & 7,500 & 7.7 & 7,800 & 47.7 \\
\hline 1969 & 7,800 & 9.1 & 7,800 & 53.0 \\
\hline 1970 & 7,800 & 9.0 & 7,800 & 56.5 \\
\hline 1971 & 7,800 & 9.5 & 7,800 & 58.6 \\
\hline 1972 & 9,000 & 10.6 & 9,000 & 55.3 \\
\hline 1973 & 10,700 & 10.1 & 10,800 & 49.6 \\
\hline 1974 & 11,400 & 10.4 & 13,200 & 39.5 \\
\hline 1975 & 11,700 & 11.4 & 14,100 & 37.1 \\
\hline 1976 & 12,600 & 11.3 & 15,300 & 37.1 \\
\hline 1977 & 13,400 & 11.9 & 16,500 & 36.3 \\
\hline 1978 & 15,000 & 12.2 & 17,700 & 40.0 \\
\hline 1979 & 15,800 & 13.2 & 22,900 & 26.7 \\
\hline 1980 & 16,500 & 13.5 & 25,900 & 22.5 \\
\hline 1981 & 17,700 & 14.5 & 29,700 & 18.8 \\
\hline 1982 & 17,800 & 17.1 & 32,400 & 17.2 \\
\hline 1983 & 17,800 & 18.0 & 35,700 & 14.7 \\
\hline 1984 & 18,900 & 19.4 & 37,800 & 15.1 \\
\hline 1985 & 19,900 & 19.5 & 39,600 & 14.3 \\
\hline 1986 & 19,100 & 20.1 & 42,000 & 13.4 \\
\hline 1987 & 19,800 & 21.7 & 43,800 & 12.7 \\
\hline 1988 & 20,000 & 22.2 & 45,000 & 13.6 \\
\hline 1989 & 18,700 & 23.6 & 48,000 & 12.2 \\
\hline 1990 & 18,200 & 23.6 & 51,300 & 10.4 \\
\hline 1991 & 15,900 & 27.3 & 53,400 & 9.1 \\
\hline
\end{tabular}


Table 2. Estimated Autocorrelations in Log Annual Earnings, 1975-1984

\begin{tabular}{|c|c|c|c|c|c|c|c|c|c|c|}
\hline Year & 1975 & 1976 & 1977 & 1978 & 1979 & 1980 & 1981 & 1982 & 1983 & 1984 \\
\hline 1975 & 1 & $\begin{array}{c}.92 \\
(.01)\end{array}$ & $\begin{array}{c}.82 \\
(.01)\end{array}$ & $\begin{array}{c}.79 \\
(.01)\end{array}$ & $\begin{array}{c}.77 \\
(.01)\end{array}$ & $\begin{array}{c}.74 \\
(.01)\end{array}$ & $\begin{array}{c}.69 \\
(.02)\end{array}$ & $\begin{array}{c}.65 \\
(.02)\end{array}$ & $\begin{array}{c}.62 \\
(.02)\end{array}$ & $\begin{array}{c}.59 \\
(.02)\end{array}$ \\
\hline 1976 & & 1 & $\begin{array}{c}.88 \\
(.01)\end{array}$ & $\begin{array}{c}.83 \\
(.01)\end{array}$ & $\begin{array}{c}.79 \\
(.01)\end{array}$ & $\begin{array}{c}.77 \\
(.01)\end{array}$ & $\begin{array}{c}.73 \\
(.02)\end{array}$ & $\begin{array}{c}.69 \\
(.02)\end{array}$ & $\begin{array}{c}.66 \\
(.02)\end{array}$ & $\begin{array}{c}.64 \\
(.02)\end{array}$ \\
\hline 1977 & & & 1 & $\begin{array}{c}.91 \\
(.01)\end{array}$ & $\begin{array}{c}.84 \\
(.01)\end{array}$ & $\begin{array}{c}.77 \\
(.01)\end{array}$ & $\begin{array}{l}.77 \\
(.01)\end{array}$ & $\begin{array}{c}.70 \\
(.02)\end{array}$ & $\begin{array}{c}.68 \\
(.02)\end{array}$ & $\begin{array}{c}.69 \\
(.02)\end{array}$ \\
\hline 1978 & & & & 1 & $\begin{array}{c}.88 \\
(.01)\end{array}$ & $\begin{array}{c}.80 \\
(.01)\end{array}$ & $\begin{array}{c}.78 \\
(.01)\end{array}$ & $\begin{array}{c}.72 \\
(.02)\end{array}$ & $\begin{array}{c}.70 \\
(.02)\end{array}$ & $\begin{array}{c}.69 \\
(.02)\end{array}$ \\
\hline 1979 & & & & & 1 & $\begin{array}{c}.87 \\
(.01)\end{array}$ & $\begin{array}{c}.84 \\
(.01)\end{array}$ & $\begin{array}{c}.78 \\
(.01)\end{array}$ & $\begin{array}{c}.73 \\
(.02)\end{array}$ & $\begin{array}{c}.71 \\
(.02)\end{array}$ \\
\hline 1980 & & & & & & 1 & $\begin{array}{c}.89 \\
(.01)\end{array}$ & $\begin{array}{c}.83 \\
(.01)\end{array}$ & $\begin{array}{c}.76 \\
(.01)\end{array}$ & $\begin{array}{c}.73 \\
(.02)\end{array}$ \\
\hline 1981 & & & & & & & 1 & $\begin{array}{c}.87 \\
(.01)\end{array}$ & $\begin{array}{c}.82 \\
(.01)\end{array}$ & $\begin{array}{c}.78 \\
(.01)\end{array}$ \\
\hline 1982 & & & & & & & & 1 & $\begin{array}{c}.89 \\
(.01)\end{array}$ & $\begin{array}{c}.82 \\
(.01)\end{array}$ \\
\hline 1983 & & & & & & & & & 1 & $\begin{array}{c}.87 \\
(.01)\end{array}$ \\
\hline 1984 & & & & & & & & & & 1 \\
\hline
\end{tabular}

Note: Numbers in parentheses are estimated standard errors. 
Table 3. Average Estimated Autocorrelations from Various Studies

\begin{tabular}{cccccc}
\hline $\begin{array}{c}\text { Order of } \\
\text { Autocorrelation }\end{array}$ & $\begin{array}{c}\text { Our } \\
\text { Table 2 }\end{array}$ & $\begin{array}{c}\text { Baker and } \\
\text { Solon } \\
(2003), \\
\text { Table } 3\end{array}$ & $\begin{array}{c}\text { Bohlmark and } \\
\text { Lindquist } \\
(2005), \\
\text { Table 2 }\end{array}$ & $\begin{array}{c}\text { Our W-2 } \\
\text { Data for } \\
1980-1991\end{array}$ & $\begin{array}{c}\text { Our Social } \\
\text { Security } \\
\text { Data for } \\
1980-1991\end{array}$ \\
\hline 1 & .89 & .82 & .84 & .89 & .91 \\
2 & .82 & .75 & .79 & .83 & .85 \\
3 & .78 & .71 & .80 & .79 & .81 \\
4 & .75 & .69 & .73 & .74 & .77 \\
5 & .72 & .65 & .72 & .71 & .73 \\
6 & .69 & .62 & .69 & .67 & .70 \\
\hline
\end{tabular}


Figure 1. Illustrative Example of Log Annual Earnings and Log Annuitized Lifetime Earnings

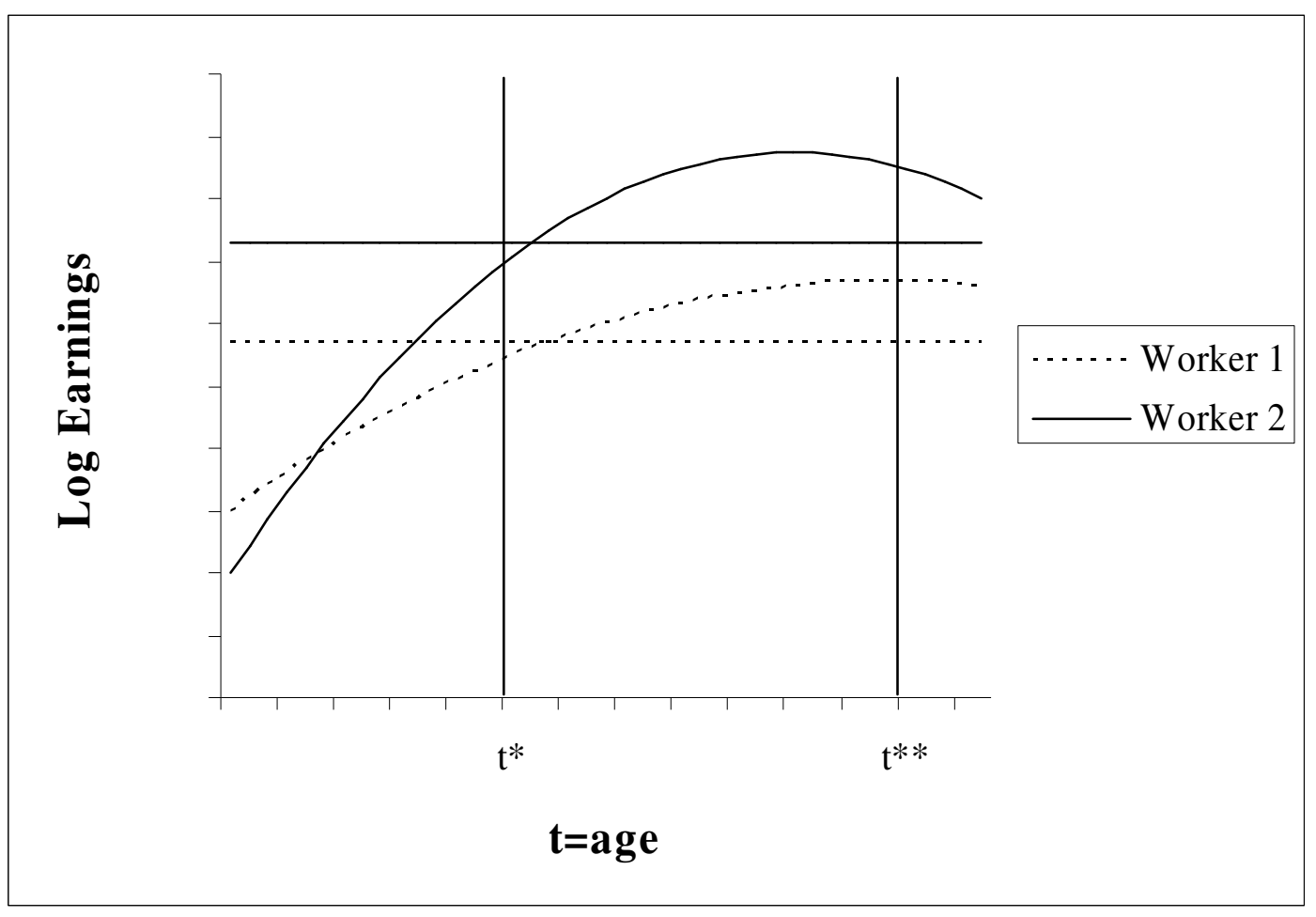

Notes: The dotted lines are for worker 1, and the solid lines are for worker 2. For each worker, the upward-sloping line depicts log annual earnings by age, and the horizontal line depicts log annuitized lifetime earnings. 
Figure 2. Main Estimates of $\lambda_{t}$ and $\theta_{t}$

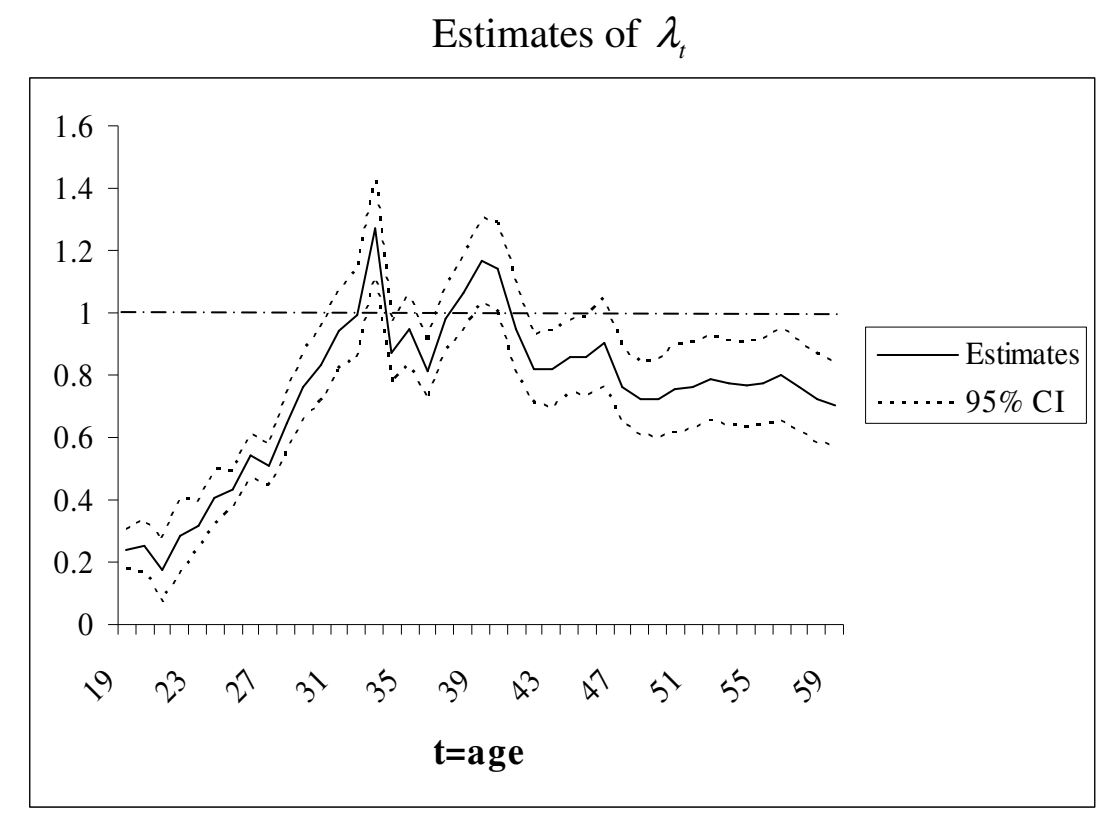

Estimates of $\theta_{t}$

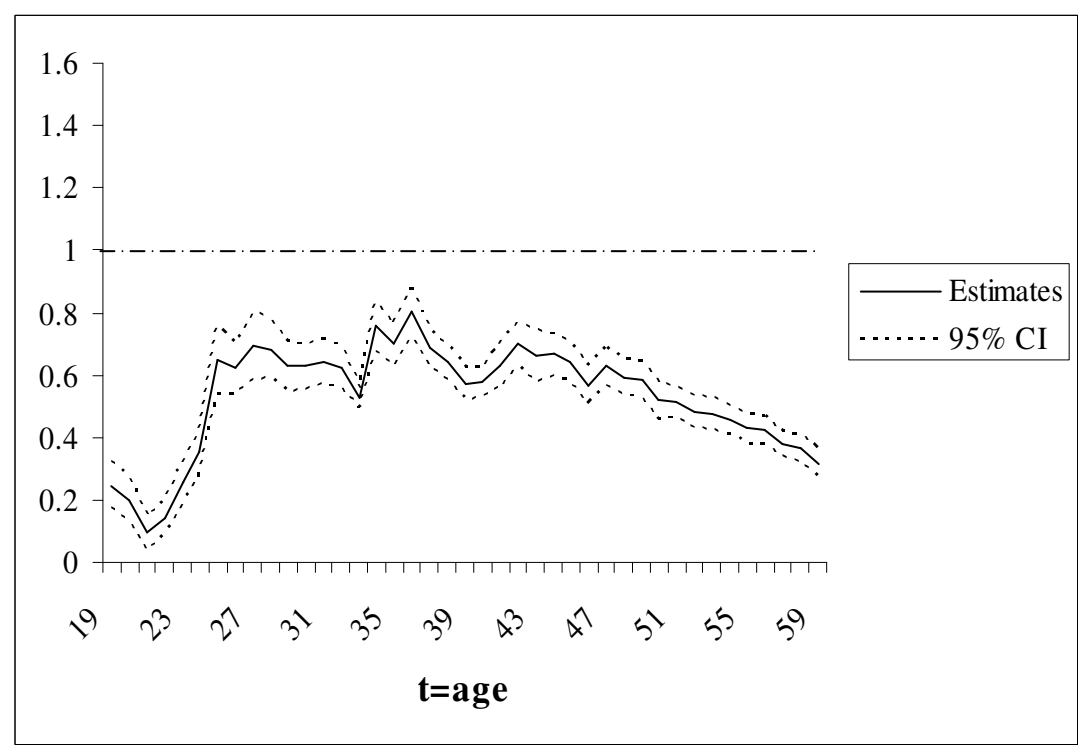

Notes: The solid lines graph the parameter estimates, and the dotted lines are 1.96 estimated standard errors above and below the solid lines. 
Figure 3. Alternative Estimates of $\lambda_{t}$ and $\theta_{t}$

Estimates of $\lambda_{t}$

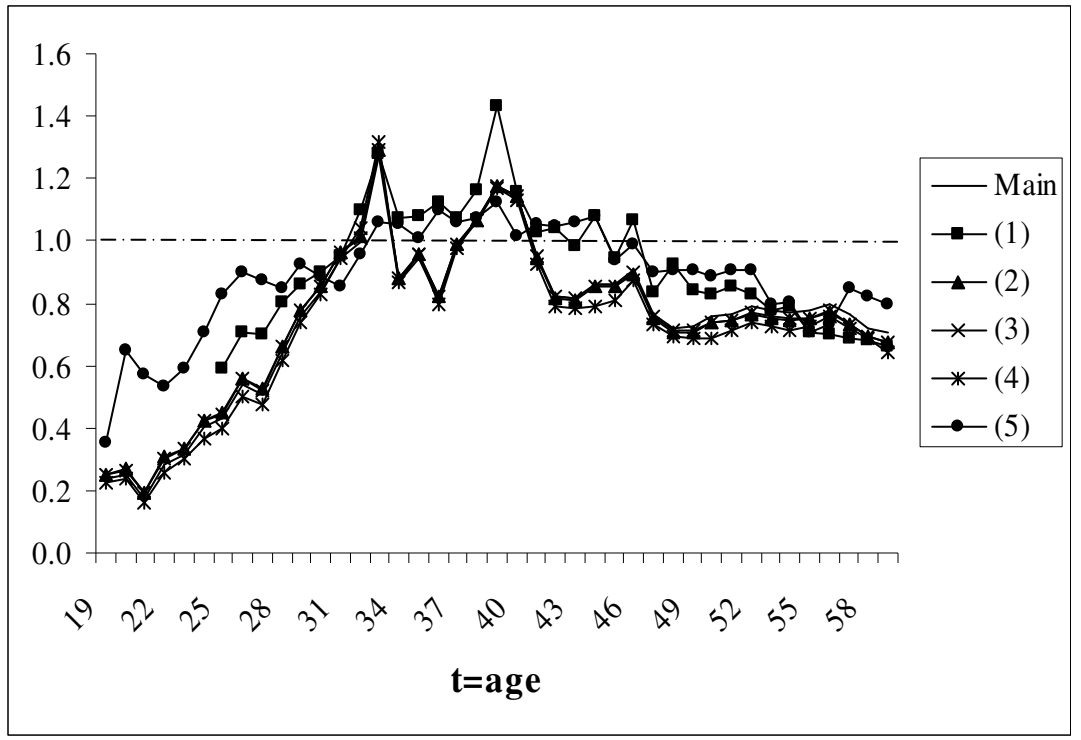

Estimates of $\theta_{t}$

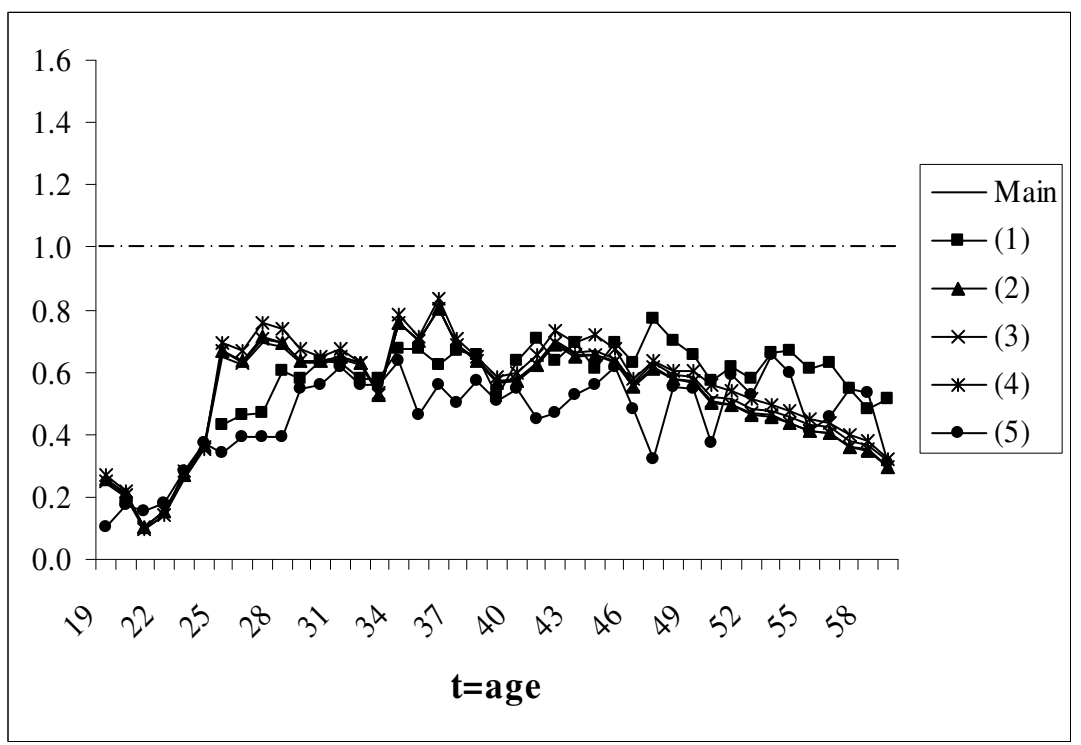

Notes: The plotted estimates are from five different analyses:

Main - main estimates copied from figure 2

(1) - same as main, but dropping zeros and estimating one-limit Tobits

(2) - same as main, but using 0.04 real interest rate

(3) - same as main, but discounting with one-year T-note interest rates

(4) - same as main, but weighting by inverse probabilities of selection

(5) - Swedish estimates from Bohlmark and Lindquist (2005) 


\section{$\underline{\text { Appendix }}$}

A. Full estimated autocovariance matrix

The complete $41 \times 41$ matrix of estimated variances and autocorrelations from the first step of our estimation procedure is in the spreadsheet matrix.xls, available in a zip file at http://www.msu.edu/ haider.

B. Procedure for imposing positive semi-definiteness

To implement the simulation in the second step of our estimation procedure, we need the estimated autocovariance matrix of log earnings for 1951-1991 to be positive semi-definite (as the true one must be). Our element-by-element method of estimation does not guarantee that $\widetilde{\Omega}$, our initial estimate of the autocovariance matrix, is positive semi-definite, and it occasionally is not in some versions of our estimation. In those instances, our procedure for imposing the restriction of positive semi-definiteness begins by characterizing the population autocovariance matrix $\Omega$ in terms of the Cholesky decomposition $\Omega=T T^{\prime}$ where $T$ is lower triangular. The matrix $\Omega$ is positive semidefinite if and only if the diagonal elements of $T$ are non-negative. Therefore, to obtain a positive semi-definite estimate $\hat{\Omega}$, we choose $\hat{T}$ to minimize the distance between $\hat{\Omega}=\hat{T} \hat{T}^{\prime}$ and $\widetilde{\Omega}$ subject to the constraint that the diagonal elements of $\hat{T}$ are nonnegative. We measure distance as the sum of squared deviations between the distinct elements in $\hat{\Omega}$ and the corresponding elements in $\widetilde{\Omega}$. On the occasions when $\widetilde{\Omega}$ is not positive semi-definite, it comes close, so the elements in $\hat{\Omega}$ differ only slightly from those in $\widetilde{\Omega}$. We are very grateful to Jeff Wooldridge for his help in devising this method. 


\section{Estimates plotted in figure 2}

Table A1 provides the point estimates and associated standard error estimates corresponding to figure 2 in the paper. The 95 percent confidence intervals plotted in figure 2 are 1.96 estimated standard errors above and below the point estimates. The standard error estimates are based on the following bootstrap procedure. We conduct 50 iterations of choosing new samples of size 821 by sampling with replacement from our original sample of 821 individuals. For each of the bootstrap samples, we perform our entire sequential estimation procedure to generate estimates of $\lambda_{t}$ and $\theta_{t}$ for each $t$. For each parameter estimate plotted in figure 2 and listed in table A1, we estimate the standard error with the sample standard deviation of that parameter estimate across the bootstrap replications. The only departure from the estimation procedure used in our main analysis is that, in the bootstrap replications, we use a different method for imposing positive semi-definiteness of the autocovariance matrix. Instead of using the method described in the previous section, we perform a spectral decomposition on the estimated autocovariance matrix, set the negative eigenvalues to zero, and then remultiply the various elements together. This change greatly reduces the computational time, and we have verified that the resulting positive semi-definite matrix is very similar to what would be obtained using the previous method. Furthermore, to the extent that a "closer" positive semi-definite matrix would exist, this simplification can be interpreted as introducing noise into our bootstrap procedure, which probably would produce overly large confidence intervals. 
D. Estimates for five-year averages of log earnings

Many intergenerational earnings mobility studies have attempted to reduce errorsin-variables bias by averaging father's log earnings over multiple years. To explore the extent to which such averaging reduces bias, in figure A1 we repeat the analysis in figure 2 except that the new estimates of $\theta_{t}$ are for five-year averages of log annual earnings, rather than for single years. For example, the observation plotted for age 30 is based on a five-year average for ages 28-32. As expected, the $\hat{\theta}_{t}$ trajectory based on five-year averages is higher than the one based on single-year earnings. Nevertheless, although the estimates of $\theta_{t}$ usually exceed 0.7 over a wide age range from 26 to 46 , they never exceed 0.8 by much. This finding strongly supports the conclusion of Mazumder (2001, 2005) that even estimates based on five-year averages of the earnings variable for fathers are subject to a substantial errors-in-variables bias.

The $\hat{\lambda}_{t}$ based on a five-year average is algebraically identical to the simple average of the single-year values of $\hat{\lambda}_{t}$ for those five years. Consequently, as shown in figure $\mathrm{A} 1$, the $\hat{\lambda}_{t}$ trajectory based on five-year averages is just a smoothed version of the trajectory in figure 2. 
Table A1. Main Estimates Plotted in Figure 2

\begin{tabular}{|c|c|c|c|c|}
\hline \multirow[b]{2}{*}{ Year } & \multicolumn{2}{|c|}{$\theta$} & \multicolumn{2}{|c|}{$\lambda$} \\
\hline & Coefficient & Std. Error & Coefficient & Std. Error \\
\hline 1951 & 0.245 & 0.038 & 0.237 & 0.033 \\
\hline 1952 & 0.199 & 0.036 & 0.251 & 0.042 \\
\hline 1953 & 0.094 & 0.027 & 0.171 & 0.050 \\
\hline 1954 & 0.144 & 0.029 & 0.284 & 0.061 \\
\hline 1955 & 0.258 & 0.032 & 0.317 & 0.041 \\
\hline 1956 & 0.352 & 0.036 & 0.405 & 0.046 \\
\hline 1957 & 0.652 & 0.056 & 0.432 & 0.030 \\
\hline 1958 & 0.620 & 0.042 & 0.541 & 0.036 \\
\hline 1959 & 0.696 & 0.055 & 0.508 & 0.033 \\
\hline 1960 & 0.684 & 0.046 & 0.643 & 0.050 \\
\hline 1961 & 0.629 & 0.041 & 0.760 & 0.055 \\
\hline 1962 & 0.630 & 0.038 & 0.835 & 0.060 \\
\hline 1963 & 0.644 & 0.037 & 0.945 & 0.063 \\
\hline 1964 & 0.625 & 0.035 & 0.993 & 0.071 \\
\hline 1965 & 0.527 & 0.018 & 1.270 & 0.078 \\
\hline 1966 & 0.756 & 0.040 & 0.869 & 0.050 \\
\hline 1967 & 0.700 & 0.035 & 0.947 & 0.058 \\
\hline 1968 & 0.803 & 0.039 & 0.812 & 0.046 \\
\hline 1969 & 0.688 & 0.031 & 0.981 & 0.053 \\
\hline 1970 & 0.640 & 0.028 & 1.062 & 0.060 \\
\hline 1971 & 0.573 & 0.027 & 1.170 & 0.069 \\
\hline 1972 & 0.578 & 0.025 & 1.144 & 0.075 \\
\hline 1973 & 0.630 & 0.037 & 0.948 & 0.075 \\
\hline 1974 & 0.700 & 0.036 & 0.821 & 0.056 \\
\hline 1975 & 0.663 & 0.041 & 0.818 & 0.062 \\
\hline 1976 & 0.667 & 0.034 & 0.860 & 0.058 \\
\hline 1977 & 0.642 & 0.033 & 0.860 & 0.064 \\
\hline 1978 & 0.568 & 0.031 & 0.904 & 0.073 \\
\hline 1979 & 0.628 & 0.032 & 0.764 & 0.061 \\
\hline 1980 & 0.594 & 0.027 & 0.722 & 0.059 \\
\hline 1981 & 0.584 & 0.029 & 0.725 & 0.064 \\
\hline 1982 & 0.519 & 0.031 & 0.756 & 0.073 \\
\hline 1983 & 0.512 & 0.024 & 0.762 & 0.070 \\
\hline 1984 & 0.484 & 0.026 & 0.788 & 0.071 \\
\hline 1985 & 0.477 & 0.026 & 0.776 & 0.069 \\
\hline 1986 & 0.456 & 0.024 & 0.770 & 0.069 \\
\hline 1987 & 0.429 & 0.025 & 0.776 & 0.071 \\
\hline 1988 & 0.423 & 0.024 & 0.799 & 0.076 \\
\hline 1989 & 0.379 & 0.021 & 0.763 & 0.074 \\
\hline 1990 & 0.368 & 0.023 & 0.723 & 0.072 \\
\hline 1991 & 0.315 & 0.023 & 0.704 & 0.068 \\
\hline
\end{tabular}


Figure A1. Estimates of $\theta_{t}$ and $\lambda_{t}$ from Five-Year Averages

Estimates of $\lambda_{t}$

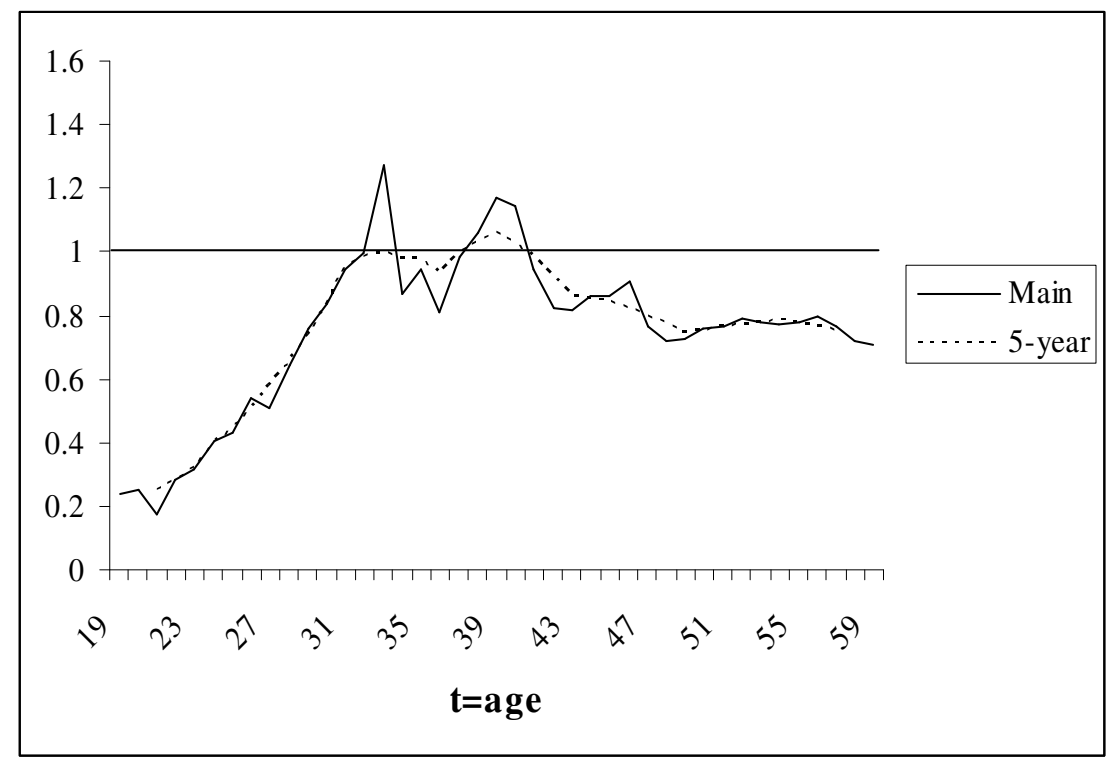

Estimates of $\theta_{t}$

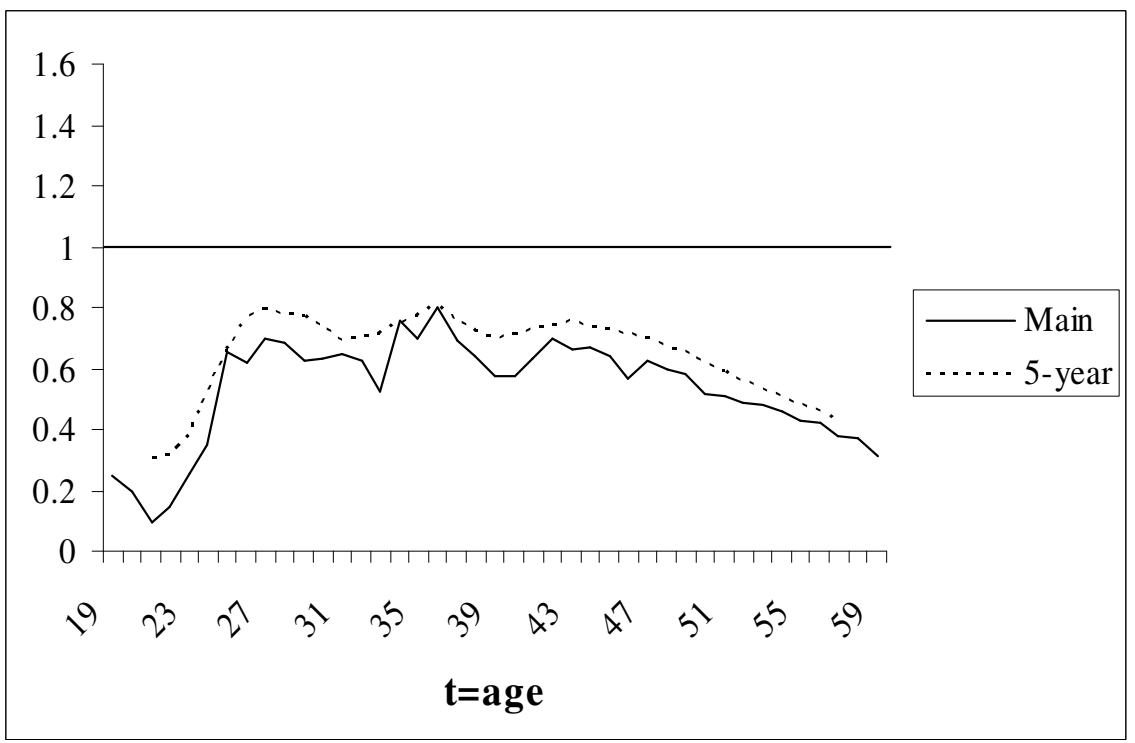




\section{$\underline{\text { References }}$}

Abowd, John M. and Card, David. "On the Covariance Structure of Earnings and Hours Changes." Econometrica, March 1989, 57(2), pp. 411-45.

Angrist, Joshua D. and Krueger, Alan B. "Empirical Strategies in Labor Economics," in Orley C. Ashenfelter and David Card, eds., Handbook of labor economics, Vol. 3A. Amsterdam: North-Holland, 1999, pp. 1277-366.

Baker, Michael. "Growth-Rate Heterogeneity and the Covariance Structure of LifeCycle Earnings.” Journal of Labor Economics, April 1997, 15(2), pp. 338-75. Baker, Michael and Solon, Gary. "Earnings Dynamics and Inequality among Canadian Men, 1976-1992: Evidence from Longitudinal Income Tax Records.” Journal of Labor Economics, April 2003, 21(2), pp. 289-321.

Bjorklund, Anders. “A Comparison between Actual Distributions of Annual and Lifetime Income: Sweden 1951-89." Review of Income and Wealth, December 1993, 39(4), pp. 377-86.

Bohlmark, Anders and Lindquist, Matthew J. "Life-Cycle Variations in the Association between Current and Lifetime Income: Country, Gender and Cohort Differences." Unpublished, Swedish Institute for Social Research, Stockholm University, 2005.

Bound, John and Krueger, Alan B. "The Extent of Measurement Error in Longitudinal Earnings Data: Do Two Wrongs Make a Right?” Journal of Labor Economics, January 1991, 9(1), pp. 1-24.

Bound, John and Solon, Gary. "Double Trouble: On the Value of Twins-Based Estimation of the Return to Schooling." Economics of Education Review, April 1999, 18(2), pp. 169-82. 
Friedman, Milton. A theory of the consumption function. Princeton: Princeton University Press, 1957.

Gottschalk, Peter and Moffitt, Robert. "The Growth of Earnings Instability in the U.S. Labor Market.” Brookings Papers on Economic Activity, 2:1994, pp. 217-54.

Grawe, Nathan D. "Lifecycle Bias in Estimates of Intergenerational Earnings Persistence." Labour Economics, forthcoming.

Haider, Steven J. "Earnings Instability and Earnings Inequality of Males in the United States: 1967-1991." Journal of Labor Economics, October 2001, 19(4), pp. 799-836.

Haider, Steven and Solon, Gary. "Nonrandom Selection in the HRS Social Security Earnings Sample.” Working Paper No. 00-01, RAND Labor and Population Program, 2000.

Jenkins, Stephen. 'Snapshots versus Movies: 'Lifecycle Biases' and the Estimation of Intergenerational Earnings Inheritance.” European Economic Review, July 1987, 31(5), pp. 1149-58.

Juster, F. Thomas and Suzman, Richard. "An Overview of the Health and Retirement Study." Journal of Human Resources, 1995, 30(Supplement), pp. S7-56.

Kane, Thomas J., Rouse, Cecilia Elena and Staiger, Douglas. "Estimating Returns to Schooling When Schooling Is Misreported.” Working Paper No. 6721, National Bureau of Economic Research, 1999.

Kim, Bonggeun and Solon, Gary. "Implications of Mean-Reverting Measurement Error for Longitudinal Studies of Wages and Employment." Review of Economics and Statistics, February 2005, 87(1), pp. 193-6. 
Lillard, Lee A. "Inequality: Earnings vs. Human Wealth.” American Economic Review, March 1977, 67(2), pp. 42-53.

Mazumder, Bhashkar. “The Mis-Measurement of Permanent Earnings: New Evidence from Social Security Earnings Data.” Working Paper No. 2001-24, Federal Reserve Bank of Chicago, 2001.

Mazumder, Bhashkar. "Fortunate Sons: New Estimates of Intergenerational Mobility in the U.S. Using Social Security Earnings Data.” Review of Economics and Statistics, May 2005, 87(2), pp. 235-55.

Mincer, Jacob. Schooling, experience, and earnings. New York: National Bureau of Economic Research, 1974.

Modigliani, Franco and Brumberg, Richard. "Utility Analysis and the Consumption Function: An Interpretation of Cross-Section Data," in K. K. Kurihara, ed., PostKeynesian economics. New Brunswick: Rutgers University Press, 1954, pp. 388436.

Reville, Robert T. "Intertemporal and Life Cycle Variation in Measured Intergenerational Earnings Mobility.” Unpublished, RAND, 1995.

Social Security Administration. Annual statistical supplement to the Social Security Bulletin. Washington, DC: Social Security Administration, 1999.

Solon, Gary. "Intergenerational Mobility in the United States." American Economic Review, June 1992, 82(3), pp. 393-408.

Solon, Gary. "Intergenerational Mobility in the Labor Market," in Orley C. Ashenfelter and David Card, eds., Handbook of labor economics, Vol. 3A. Amsterdam: NorthHolland, 1999, pp. 1761-800. 
Wooldridge, Jeffrey M. Introductory econometrics: a modern approach. Mason, $\mathrm{OH}$ : Thomson, $3^{\text {rd }}$ ed., 2006. 